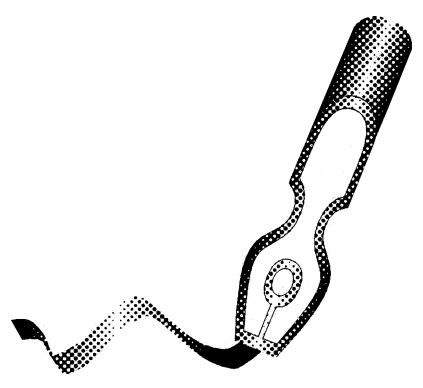

\title{
Tareas por cumplir
}

Los propósitos u objetivos de una revista médica pueden resumirse en tres:

1. Promover y estimular el desarrollo del conocimiento médico-científico lo que se logra a través del estudio y conocimiento de los trabajos publicados en ellas y su aplicación en la práctica médica diaria.

2. Facilitar el perfeccionamiento continuo de los médicos, lo que sin lugar a dudas, es un desafío permanente para todos los otorrinolaringólogos atendiendo al vertiginoso desarrollo de la medicina y de sus herramientas, particularmente las ciencias de la informática, pues vivimos en una época en que el conocimiento ha superado a la sabiduría.

3. Difundir los trabajos clínicos y de investigación desarrollados tanto en el país como fuera de él.

De acuerdo a estos parámetros nuestra Revista que ya cumple 71 años de publicación ininterrumpida, lo que la convierta en una revista líder en Latinoamérica, ha logrado con éxito conseguir parcialmente algunos de estos objetivos, debiendo ser tarea prioritaria del Comité Editorial luchar para optimizar la calidad científica de las publicaciones particularmente de los Artículos de Investigación y mejorar y abrir la difusión de la Revista a todo el ámbito latinoamericano y también al resto del mundo.

Esta no es una tarea fácil y necesita del trabajo constante de sus editores, lo que pone en discusión el tema, que en un momento probablemente cercano, la Revista debería profesionalizarse para poder abocarse de lleno a cumplir con estos objetivos.

Una de las metas cercanas deberá ser como lo plantea nuestro Director: que la Revista en su versión electrónica debería publicarse a la brevedad tanto en español como en inglés, tal como lo hacen actualmente las revistas homónimas de España y Brasil que gozan de amplio prestigio. El idioma inglés es la lengua franca científica mundial y no podemos ignorarlo por más tiempo, so pena de cerrar la lectura de sus artículos a muchos médicos que no sean hispanoparlantes.

Otro de los propósitos debe ser publicar la revista cada tres meses, lo cual automáticamente mejora su presencia y visibilidad internacional que permita postular nuestra Revista a ser aceptada en las principales bases de datos del área biomédica u otras redes internacionales de divulgación científica. Pienso que con el esfuerzo mancomunado de todos los especialistas nacionales es posible cumplir con este objetivo. 
Existe un antiguo refrán sobre la importancia de la divulgación que dice que "el esturión pone 2 a 3 millones de huevos en cada desove, pero nadie lo sabe, en cambio la gallina que pone sólo un huevo en cada desove, todo el mundo se entera porque cacarea". En tal sentido una tarea urgente de nuestra Revista es mejorar la difusión de ella, particularmente en su versión impresa o física. Hoy en día es fácil obtener la dirección de casi todas las Sociedades de Otorrinolaringología del mundo, y por ello debería enviársela a todas ellas, proponiendo incluso canje con las revistas que puedan editar estas sociedades. De igual forma, deberían enviarse revistas impresas a los editores de las principales revistas otorrinolaringológicas particularmente las europeas, que no tienen tanto fin de lucro como las estadounidenses, solicitando intercambio, lo cual además de permitir la difusión de nuestra Revista ayudaría a enriquecer la biblioteca de la Sociedad. De igual manera debería enviarse la revista a los principales centros de estudio de la especialidad, particularmente a las escuelas de medicina y bibliotecas de mayor prestigio internacional.

Finalmente hacer un nuevo esfuerzo e invitar a un mayor grupo investigadores internacionales de prestigio a incorporarse al Comité Científico Internacional, lo cual automáticamente atraería el interés de muchos médicos por publicar en nuestra Revista.

En resumen es un trabajo arduo y un hermoso desafío para el Comité Editorial luchar para tener éxito en cumplir con estos nobles objetivos, recordando que no se progresa mejorando lo que ya está hecho sino esforzándose por lograr lo que aún queda por hacer. 